\title{
"Las plumas son para las gallinas": masculinidad, plumofobia y discreción entre hombres
}

\author{
"Las plumas son para las gallinas»: Masculinity, \\ Effeminophobia and Discretion among Men
}

\author{
Saúl Ariza ${ }^{1}$ \\ Universidad Autónoma de Madrid
}

\section{RESUMEN}

Este trabajo parte de la premisa de que se ha producido una masculinización de los hombres identificados como homosexuales a partir de la segunda mitad del siglo XX. Esto ha conllevado una transformación del modelo de deseo homosexual masculino y un rechazo de la pluma, es decir, de las actitudes o formas de actuar consideradas como afeminadas. Después de tres años de experiencia etnográfica en diferentes ciudades españolas, en chats y aplicaciones de contactos para hombres, bares nocturnos y centros deportivos, utilizo mi participación en la aplicación Wapo para mostrar cómo ciertos ideales relacionados con la masculinidad y la discreción, así como los discursos contra la pluma, hegemonizan la interacción en este tipo de espacios. También muestro que las diferencias observadas respecto a estas normatividades dependen de la cercanía geográfica a lo que he llamado epicentros de lo gay. Asimismo, analizo diferentes formas en que los hombres a los que he entrevistado experimentan estas normatividades. Finalmente, argumento que la plumofobia es una forma de control de género entre hombres que sirve para recuperar el capital simbólico asociado a la masculinidad y conservar así los privilegios sociales asociados a la hombría.

Palabras clave: Homosexualidad; Pluma; Plumofobia; Homonormatividad; Aplicaciones de Contactos.

\section{SUMMARY}

The starting point for this paper is the premise that there has been a masculinization of men identified as homosexuals as of the second half of the twentieth century. This has involved a transformation of the model of male homosexual desire that has implied a rejection of attitudes and behaviors considered as effeminate, which are known as pluma or plumas in Spain. After three years of ethnographic experience in several Spanish cities, in chats and hookup apps for men, night clubs and sports centres, I have used my participation in the app Wapo to show how certain ideals related to masculinity and discretion, as well as discourses against effeminate men, hegemonize interaction in these kinds of settings. I also show the differences observed regarding these regulations depending on geographical proximity to what I have called epicenters of gayness. In addition, I analyse different ways in which the men I have interviewed experience these normativities. Finally, I argue that effeminophobia is a form of gender control among men that serves to recover the symbolic capital associated with masculinity and thus preserve the social privileges associated with manhood.

Keywords: Homosexuality; Effeminophobia; Sissyphobia; Homonormativity; Hookup apps.

\footnotetext{
${ }^{1}$ Correo electrónico: saul.ariza@uam.es. ORCID iD: <https://orcid.org/0000-0003-2769-5466>.
} 


\section{INTRODUCCION}

Los hombres identificados como bomosexuales ${ }^{2}$ en las sociedades euroamericanas contemporáneas, así como sus representaciones, han agenciado una fuerte masculinización. Esta se inicia según algunos a mediados del siglo XX (Marshal 1981; Hekma 1994), y se desarrolla según otros desde los años 70, con la aparición del modelo gay y la figura del gay macho man (Blachford 1981; Gough 1989; Edwards 1990 y 1994; Guasch 1991, 2000 y 2011; Segal 1994; Levine 1998). Desde entonces y hasta ahora, las concepciones culturales de la masculinidad han pasado a ser un elemento central en el mundo simbólico de los hombres con prácticas homosexuales, así como en la configuración de las subculturas gays (Harris 1999; Guasch 2011). Esto ha conllevado, en gran medida, un rechazo de las formas de actuar consideradas como femeninas, así como de las imágenes que representaban a los homosexuales como hombres afeminados (Humphries 1985; Forrest 1994). Teniendo esto en cuenta, es difícil sostener que la homosexualidad masculina sea por definición contraria a las acepciones de la masculinidad, o que los homosexuales sean esencialmente contrarios a los preceptos normativos de género (como se extrae de Kimmel 1994; Connell 1995; WelzerLang 2002; Cabezas y Berná 2013).

Con este marco teórico y crítico, desde el otoño de 2014 hasta el verano de 2017 , realicé trabajo de campo en lugares que formaban o pasaron a formar parte de mi vida diaria. Durante tres años, mi participación en chats y aplicaciones de contactos, zonas y bares de ocio nocturno y centros deportivos, en las ciudades de Córdoba, Sevilla y Madrid, solapó mi experiencia personal con la de la investigación, convirtiendo esta en lo que considero una experiencia etnográfica. El objetivo de esta experiencia, que se extiende hasta la actualidad, ha sido abordar de forma antropológica las construcciones y normas de la masculinidad en los hombres que mantienen prácticas homosexuales, y sobre cómo estos podían reproducir las estructuras de la dominación masculina.

Uno de los lugares donde estas normas y estructuras se manifestaban de forma evidente fueron las aplicaciones de contactos para hombres. En este trabajo, a través de mi experiencia etnográfica en la aplicación de contactos Wapo, muestro cómo las normas de la masculinidad y la discreción, así como los discursos contra la pluma, o plumofobia, hegemonizan la interacción en este tipo de espacios, siendo esto reflejo de una realidad homosexual más amplia. Para este análisis, he considerado la aplicación como un campo sexual que refleja, a la vez que produce, las normas sociales que se dan en ella (Martin y George 2006; Green 2008, 2011 y 2014). En este sentido, reflejo cómo los nombres de los perfiles, las descripciones y las imágenes que aparecen en Wapo crean, al mismo tiempo que reproducen, normatividades respecto a la masculinidad que se traducen en la idea de que hay una forma de ser un hombre de verdad, al cual se debe dirigir el deseo homosexual masculino. También muestro cómo estas dependen de la posición geográfica respecto a lo que llamo epicentros de lo gay. Finalmente, argumento que la plumofobia es un efecto de esta masculiniza-

\footnotetext{
${ }^{2}$ Con la letra cursiva pretendo reflejar que no me estoy refiriendo a un conjunto de personas o un colectivo, sino al constructo social de ese mismo colectivo, a una representación de un conjunto de personas. Para una discusión más amplia sobre este tema, ver Ariza (en prensa).
} 
ción del hombre homosexual, una forma de control de género entre hombres que sirve como estrategia o negociación para conservar o recuperar los privilegios asociados a la hombría.

\section{SOBRE PLUMAS, PLUMOFOBIA Y APLICACIONES DE CONTACTOS}

\section{LA PLUMA Y LA PLUMOFOBIA}

La pluma, o el afeminamiento como característica del mundo homosexual masculino en España, ha sido tratada, aunque de forma limitada, en la literatura antropológica e histórica (Olmeda 2004; Valcuende del Río 2010; Cáceres y Valcuende 2014). No obstante, en muchos de estos trabajos ha sido teorizada como un modelo de expresión que se asocia tanto con lo femenino en los hombres como con lo masculino en las mujeres (véase Mira 2004; Coll-Planas 2010; Pichardo 2012). Aquí pretendo distanciarme de este tipo de planteamientos y uso el concepto de pluma -o plumassolo como la forma coloquial que se utiliza en España para referirse a los rasgos de afeminamiento — es decir, culturalmente considerados propios de las mujeres- que un hombre presenta al hablar, en sus gestos, actitudes o comportamientos ${ }^{3}$. Este fue el significado que dieron al concepto todos y cada uno de los participantes a los que entrevisté a lo largo de la experiencia etnográfica y el que aparecía en los perfiles de Wapo.

A pesar de estas referencias a la pluma, el concepto de plumofobia-lo que haría referencia a la fobia al comportamiento afeminado en los hombres - ha sido apenas teorizado. En inglés, nombrada como effeminophobia o sissyphobia, también ha sido escasamente tratada (Richardson 2009; Eguchi 2011; Annes y Redlin 2012), y no siempre en un contexto académico (Bergling 2001). Es en este contexto no académico donde recientemente he podido observar un mayor uso del concepto. En mayo de 2017, con motivo del World Gay Pride 2017 en Madrid, se publicaron dos noticias en periódicos digitales, eldiario.es (Borraz 2017) y El País (Abundancia 2017), escritas por dos mujeres, respectivamente. No obstante, desde la perspectiva que defiendo en este trabajo, el problema de estos acercamientos y campañas es que, en un intento de ser inclusivas, la plumofobia es definida en estas publicaciones como "un tipo de discriminación que penaliza a aquellos que no responden a las expectativas de lo que se supone que es ser hombre o mujer" (Borraz 2017) o una norma o realidad por la que "puedes ser gay o lesbiana, pero que no se note" (Abundancia 2017). Sin embargo, las realidades a las que se refieren en ambos artículos, o los estudios en los que se basan, como el aparecido en el Gay Times (Withey 2016), hablan exclusivamente de hombres. Este último estudio, llevado a cabo por Cal Strode, revelaba que un $57 \%$ de los hombres usuarios de Grindr que se definían como "straight acting" —equivalente en Wapo a expresiones como "con pinta hetero" - creían que sus colegas afeminados daban una mala reputación al colectivo homosexual masculino. Strode entrevistó a doscientos ochenta hombres identificados como gays del Reino Unido y

\footnotetext{
3 Según el Diccionario de la Real Academia Española, en su versión del 2017, un uso coloquial de pluma es: 'afeminamiento en el habla o los gestos de un varón'.
} 
California y comparó las opiniones de aquellos que se denominaban a sí mismos como "straight acting" con el resto. Los datos revelaron que estos habían sufrido un $33 \%$ menos de episodios de homofobia en la escuela que sus compañeros con pluma, y el $35 \%$ estaban más de acuerdo con los heterosexuales que con los gays.

En este sentido, considero que usar el concepto plumofobia para definir una hipotética realidad de las mujeres es inadecuado. Defiendo que este uso constituye una visión androcéntrica - y gaycéntrica - por la cual la realidad de las mujeres aparece como una imagen en el espejo de la realidad de los hombres (Blackwood 1985). Aunque algunas mujeres puedan aplicar para sí mismas el concepto de pluma y, por ende, el de plumofobia, defiendo que esto se debe a la influencia de este tipo de teorizaciones, más que a un uso social de facto de la palabra para referirse a mujeres. En España, en la práctica social, las palabras que se han utilizado para referirse a mujeres consideradas como masculinas han sido otras, como marimacho, machorra o camionera ${ }^{4}$. Parto de que las realidades sociales y sexuales de las mujeres, sin duda diferentes a las de los hombres, deberán ser estudiadas con sus especificidades y tener sus propias palabras, sin que asumamos que son las mismas que usan $-\mathrm{y}$ se usan para- ellos.

\section{APLICACIONES DE CONTACTOS, MASCULINIDAD, PLUMOFOBIA Y DISCRECIÓN}

Las aplicaciones móviles de contactos han pasado a ocupar un lugar importante en la vida de los hombres con prácticas homosexuales (Blackwell, Birnholtz y Abbott 2015; Jaspal 2017) y, en consecuencia, se han realizado estudios muy diversos en ellas, especialmente en Grindr (Batiste 2013; Blackwell, Birnholtz y Abbott 2015; Ahlm 2017; Bonner-Thompson 2017; Jaspal 2017; Miles 2017; Enguix y Gómez 2018; Yeo y Fung 2018). Algunas de estas investigaciones han tratado la cuestión de la masculinidad (Bonner-Thompson 2017; Enguix y Gómez 2018), a veces asociada a la discreción o la gestión de la identidad (Ward 2008; Miller 2015; Reynolds 2015; Ahlm 2017; Jaspal 2017).

De forma coincidente, el único trabajo publicado en español respecto a una investigación realizada en Wapo — llamada Bender por entonces - aborda también el tema del rechazo hacia la pluma en aplicaciones de contactos (Gómez Beltrán 2016). Sin embargo, en este trabajo no se utiliza el concepto plumofobia, sino el de "homofobia interiorizada" (como también en Bord 2013; Pichardo 2012). Como afirmé con anterioridad, y de forma contraria a este tipo de conceptualizaciones, aquí no analizo la plumofobia como una expresión de homofobia interiorizada, sino como una forma de control de género entre hombres, compatible con la visión y la experiencia positiva de la práctica de la homosexualidad. Considero que ambos conceptos no son equivalentes, y enfatizo que, antropológicamente hablando, las cuestiones de práctica e identidad sexual son analíticamente independientes a las cuestiones de práctica e identidad de género (Bolin 1996). En este sentido, argumento que el concepto de plumofobia debe hacer referencia a una actitud negativa sobre ciertas prácticas de género de los hombres, sin que las opciones homosexuales de los que la manifiestan

\footnotetext{
${ }^{4}$ Para consultar un estudio etnográfico sobre el entramado social y simbólico del lesbianismo en España, véase Identidades lésbicas, de Olga Viñuales (2000).
} 
tengan que crear conflicto, de forma necesaria, con sus identidades masculinas y su manera de considerarse hombres de verdad.

\section{LA EXPERIENCIA ETNOGRÁFICA EN WAPO}

Gracias a su función geolocalizadora, las aplicaciones como Wapo facilitan encuentros sexuales inmediatos en diferentes situaciones y lugares (Yeo y Fung 2018), ya que los usuarios pueden mapear la situación geográfica de otros hombres y territorializar la comunidad virtual allí activa (Batiste 2013; Wiele y Tong 2014; Couto et al. 2016). En ellos pueden aparecer datos como la edad, el peso, el rol sexual y una pequeña descripción. También pueden incluir un enlace a las cuentas de Instagram o Twitter de los usuarios. Asimismo, la aplicación da la posibilidad de subir hasta diez imágenes. Las fotografías pueden ser públicas — de acceso libre a cualquier usuario-, o privadas —en una carpeta oculta- De hecho, cualquier desnudo que se suba será ubicado como fotografía privada, aunque las imágenes de semidesnudos —es decir, donde no se enseñen los genitales_, sí están permitidas de forma pública. Las fotografías privadas pueden ser solicitadas por otros hombres para que les sean mandadas por el chat privado si el dueño del perfil da permiso para ello.

Según se anuncia para ser descargada, "Wapo es una de las aplicaciones más famosas de contactos para gays, bisexuales u hombres curiosos" ${ }^{5}$. En este sentido, uno de los motivos para elegir esta aplicación como uno de los escenarios de la experiencia etnográfica fue el carácter extendido de su uso en España, pues todos los hombres que conocía y que usaban este tipo de aplicaciones, usaban Wapo — junto con Grindr - de forma prioritaria. Más tarde, al abrirla de forma circunstancial en otras zonas de Europa, como Portugal o Reino Unido, observé que en ella aparecían un número reducido de usuarios, los cuales provenían mayoritariamente de España.

La investigación, tanto en la aplicación como en el resto de los lugares de participación, ha empleado una metodología exclusivamente cualitativa, observando, registrando, interpretando y, sobre todo, participando de lo que allí sucedía, haciendo de todos ellos parte de mi vida cotidiana, y al contrario, convirtiendo mi actividad personal en parte de la investigación. En Wapo, tuvo lugar en diferentes localizaciones dentro de Córdoba, Sevilla y Madrid. En esta última, participé de la actividad desde cuatro zonas distintas, dos de ellas cercanas a lo que llamaré epicentros de lo gay y dos de ellas fuera de la zonas céntricas — una limítrofe y otra más alejada-. En todas ellas, dado el carácter online de la aplicación, conectado y a la vez separado del mundo offline, los términos participación y entrevista adquirían significados muy específicos (Ardèvol et al. 2003), diferentes a los que adquirían en los otros espacios.

En este contexto, informé de mi objetivo etnográfico a los usuarios con los que mantuve entrevistas online para la investigación. Asimismo, en el contexto de mi experiencia de campo en el sentido amplio, he realizado entrevistas en persona con trece hombres distintos en diferentes localizaciones de Córdoba, Sevilla y Madrid. Sus edades estaban comprendidas entre los 17 y los 50 años. El primer contacto con diez de estos hombres fue a través de la aplicación. Estas entrevistas no tenían como finali-

\footnotetext{
${ }^{5}$ Desde Google Play para Android, en junio de 2017.
} 
dad principal hablar sobre la actividad en Wapo, aunque en todas ellas surgió el tema o fue introducido por ellos o por mí. Este trabajo tiene como objetivo principal la descripción y el análisis de la plumofobia, la masculinidad y la discreción en la interacción en Wapo, por lo que solo usaré lo que se dijo en algunas de las entrevistas para ampliar el análisis y para introducir discursos ajenos al mío propio. Los nombres de los perfiles que nombro aquí han sido modificados, siempre guardando el sentido original de los mismos, dado su valor simbólico. Los nombres propios de los participantes en las entrevistas también han sido cambiados.

\section{MASCULINIDAD, PLUMOFOBIA Y DISCRECIÓN EN WAPO}

Respecto al tema que abordo en este trabajo, he dividido en tres tipos las prácticas discursivas encontradas en Wapo: a) las que hacen apología o requerimiento de la masculinidad; b) las que hacen campaña contra la feminidad; y c) las que hacen apología o requerimiento de la discreción. Estos tres elementos pueden ir unidos de una forma u otra en los distintos perfiles. En este trabajo me he centrado en las prácticas discursivas lingüísticas, aunque un análisis de las imágenes, como apoyo de los discursos, o incluso cuando no hay discurso, es también imprescindible.

\section{APOLOGÍA Y REQUERIMIENTO DE LA MASCULINIDAD}

Muchos de los perfiles en Wapo tienen a la masculinidad como elemento central, ya sea porque el sujeto hace de ella su característica principal, porque la busca en otros perfiles o, lo que suele ser más común, por ambas cosas a la vez. Esto es evidente, no solo en la práctica discursiva lingüística, sino también en el discurso de la imagen. La autopresentación como masculino puede traducirse en perfiles que, en su nombre de perfil, ya utilizan adjetivos directamente relacionados con la masculinidad. De hecho, muchos perfiles tienen como nombre de perfil un simple Masculino o Machote. Otros asociaban sus nombres de perfil con actividades deportivas o de gimnasio, como Mascgym, Deportmasc o Personal Trainer.

La búsqueda de masculinidad también puede observarse en muchas descripciones de los perfiles, en los que suelen aparecer frases como "machote para machote", que explicitan la consideración de uno mismo como poseedor simbólico de la masculinidad y buscador de esa misma cualidad en la pareja sexual que se busca. Suelen buscarse "solo tíos masculinos", mientras se muestran fotos, muchas veces sin rostro, en las que aparecen ellos mismos en ropa deportiva, haciendo ejercicios de musculación en el gimnasio. Latino45 escribía en su perfil: "Busco un tío reservado, varonil y delgado, soltero y buena gente para ver la tele abrazaditos. Me encanta el sexo oral, también conversar, besar y tomar unas cañas viendo el fútbol".

El requerimiento de masculinidad se hace en diversos tonos, pero está presente de forma casi hegemónica. Aunque se busque algo que vaya más allá del encuentro sexual, esta es un requerimiento que puede aparecer en forma de: "Masculinidad, educación y buen rollo. Lo demás ya se verá». La búsqueda de masculinidad puede traducirse también en la búsqueda de elementos masculinos. Un hombre extranjero de 
42 años, alto y atlético, el cual pasaba una temporada en Sevilla, decía en su perfil: "Me gustan las barbas, las piernas fuertes y peludas", y a continuación describía sus medidas: su altura, su peso y los centímetros que medía su pene. De esta forma, expresaba los elementos relacionados con la hombría que buscaba en otros hombres, así como también los medidores de la suya.

En Wapo pueden encontrarse con facilidad perfiles de parejas que buscaban sexo, juntos o por separado, y que reproducen también, juntos o por separado, los elementos de esta teatralidad simbólica masculina. Por ejemplo, una pareja abierta residente en Sevilla, formada por dos hombres de alrededor de 37 años, cada uno de los cuales tenía su perfil en Wapo, incluía imágenes de rostro y otras fotografías muy elaboradas, parecidas a las que podemos encontrar en una revista gay. En ellas posaban y mostraban cuerpos atléticos llenos de vello y rostros con barba. Uno de ellos decía: "Vello y barba es un plus". De este modo, teatralizaban los mismos elementos que consideraban "un plus", relacionados con un modelo de masculinidad gay, surgido a su vez de una visión hiperbólica de un modelo masculino heterosexual (Sabuco y Valcuende 2003).

Por tanto, la búsqueda de masculinidad puede verse acompañada también de una búsqueda de similitud, asumiendo que uno encarna o es un hombre masculino y merece estar acompañado de otro hombre de verdad: "Masculino por igual". Chico29 se definía a sí mismo como un "chico masculino, sencillo y deportista buscando similar para pasar buenos ratos". Estas cualidades se miden a veces cuantitativamente en forma de un porcentaje de masculinidad: "Tío $100 \%$ masculino por similares, paso de plumas", decía Masculino25. En su perfil, Futbolero29 se describía, y definía sus requerimientos, de la siguiente forma: "Masculino discreto, nada de ambiente y sin malos rollos, busco tío como yo $100 \%$ masculino y discreto, no maduros ni peña que no esté en Sevilla". En esta última exigencia puede verse también la inmediatez geográfica que muchos buscan en los encuentros.

\section{DESEROTIZACIÓN Y DENOSTACIÓN DE LA PLUMA}

Es común encontrar en la aplicación discursos que hacen una explícita denostación de la pluma, con frases como o "las plumas dentro del gallinero", "las plumas para las gallinas" ${ }^{6}$ " "las plumas para los animales" o "las plumas para el edredón". Otra forma de denostar a los hombres considerados con pluma es hacer una especie de comparación entre lo femenino y lo viril, donde lo primero es siempre la carga negativa, empleando frases como esta de otro hombre de 37 años: "No a niñat@s ni a depilados. Sí a tíos-tíos adultos de cuerpo y maduros de mente". La burla también es frecuente, dando rienda suelta a un humor que incluye sentencias como las de este hombre de 33 años: "Si se te ha ido la pinza (de depilar), o confundes musculado con masculino no nos vamos a llevar bien". En este caso, se hace una clara referencia a un tipo

\footnotetext{
${ }^{6}$ Encontré este discurso por primera vez en el perfil de uno de los hombres que formaban la pareja abierta de Sevilla a la que me he referido en anteriormente. A él, en días distintos, pertenecen las dos primeras variantes que he especificado, pero después lo he encontrado con diferentes variantes, como las que cito, en los diferentes lugares de mi trabajo de campo.
} 
de esencialismo, en el que las virtudes y características de un hombre no se ganan con el esfuerzo, como el que lleva muscularse en el gimnasio. Esto mismo también puede verse en el siguiente perfil de un hombre de 34 años, en el que lo negativo tiene género femenino: "Abstenerse las típicas mamarrachas ${ }^{7}$ que no saben lo que quieren. Prefiero un tío con mente a un tío con cuerpo. Es difícil encontrar un tío inteligente. Al gimnasio podemos ir todos". También puede leerse que "la masculinidad no es una apariencia, [sino que] es una actitud", como escribía un hombre de 31 años en Sevilla. Esta idea puede estar tan recalcada que la misma palabra "actitud" puede constituir parte del nombre del perfil, como es el caso de Actitud29: " $\uparrow^{8}$ masc, majo, diurno, trabajador, gaymer, gym, deporte, naturaleza... Busco $\downarrow$ masc, majo, diurno... [...] Planes: bici, Play ${ }^{9}$, playa, senderismo, gym, cerves, deporte, viajes".

La masculinidad es asociada en otras ocasiones a lo normal. A Moreno23 le iban "los tíos normales, masculinos... con carácter". Clásico35 afirmaba: "Soy un tío normal, clásico y masculino. No me gusta la pluma". "Normal, masculino", se definía otro hombre de 36 años. De esta forma, en estas ocasiones se establece que la normalidad de un hombre es comportarse de manera masculina y, en consecuencia, los hombres que presenten o digan presentar algún tipo de feminidad parecen quedar excluidos del sistema de deseo. Muchos hombres suelen dejar muy claro en sus perfiles que buscan, como afirmaba Masculino28, "solo tíos masculinos". Con frecuencia, y como describiré más adelante, esta búsqueda de hombres masculinos se une a un requerimiento de discreción, como es el caso de Masculino, que buscaba "solo gente masculina y discreta". Este grado de masculinidad del que algunos se apropian simbólicamente va, en muchas ocasiones, unido al grado proporcional de feminidad que se desprecia en los otros. Como ya mencioné, Masculino25 afirmaba en su perfil: "Tío $100 \%$ masculino por similares, paso de plumas".

A veces se hace palpable una especie de falsa tolerancia en la que los chicos con pluma pueden convertirse en amigos, en todo caso, pero no sirven para nada más. Man29 afirmaba: "No me va la pluma, para una amistad me vale, algo más no". Esta idea la he visto aparecer frecuentemente en las conversaciones tenidas en el chat de la aplicación, en las entrevistas en persona, así como en mi trabajo de campo en otros espacios no virtuales, donde la deseoritización de la pluma va unida a otro discurso en el que él tiene muchos amigos "con plumón", pero "no les sirven para la cama".

\section{MASCULINIDAD Y DISCRECIÓN}

Junto con la de masculinidad, la discreción es otra de las apelaciones dominantes en los discursos usados por los hombres en la aplicación. Esta, según el perfil que

\footnotetext{
${ }^{7}$ Las cursivas dentro de las citas de los perfiles son mías, para resaltar el uso de diferentes términos relevantes.

${ }^{8}$ A veces se usan símbolos para referirse a los roles sexuales, como una flecha hacia abajo para significar que tiene un rol pasivo o una flecha para arriba para significar un rol activo. También aparecen frutas y verduras, como poner una berenjena para significar activo — como analogía del pene- o un melocotón para significar pasivo — como analogía del culo- . Kika Lorace, en su canción La reina del Grindr, hace una parodia de esto.

${ }^{9}$ Se refiere a la videoconsola PlayStation.
} 
diga tenerla o diga solicitarla $-\mathrm{O}$, frecuentemente, ambas cosas a la vez-, puede tener diferentes significados, los cuales pueden ir incluyéndose en un mismo perfil. Decir en la aplicación "soy discreto" y/o "busco discreción" puede hacer referencia a: a) que la información que se comparta en la aplicación, incluyendo la de la identidad de los participantes, las fotos intercambiadas y el encuentro o relación entre ambos, quede entre las dos personas, sin que ninguna revele nada de esto a otras; b) que tiene pareja homosexual y todo ha de quedar en secreto; c) que tiene pareja heterosexual y todo ha de quedar en secreto; d) que no tiene pareja, pero lleva una "vida hetero" - como suele aparecer- y necesita de la complicidad de la otra persona; o e) que no se identifica ni como homosexual ni bisexual y lleva sus prácticas sexuales con otros hombres de manera oculta.

A veces, el requerimiento de discreción viene por parte de perfiles que sí tienen fotografías en el mismo, incluidas de su cara, por lo que se entiende que ser discreto implica para ellos la primera opción, pudiendo ser cómplice del resto de las opciones, entendiendo discreción como complicidad (en el sentido de Connell 1995). La falta de fotografías y datos personales puede estar relacionada con el grado de "estar fuera" (Wiele y Tong 2014), por lo que la discreción va incluyendo al resto de las opciones en estos casos. Encontrar perfiles con nombres como el de Masculino y discreto es muy frecuente. Si no es en el nombre de perfil, puede estar en la descripción del interior. Podemos encontrar descripciones como esta: "Masculino, discreto y musculado. Me gustan similares en aspecto y sin pluma. Por favor no escribir sin foto". Aunque no era algo común, encontré también quien establecía un porcentaje de discreción, como hacía este hombre de 30 años en Córdoba: "Con vida 100 \% discreta y masculino. Sexo y discreción sin más rollos. Al grano". Como contrapartida, algunos perfiles hacían una crítica a esta apología de la discreción, con frases como "discreción no es igual a anonimato" o "si eres discreto, ignórame".

Finalmente, en lo que quiero centrarme en este trabajo no es en la relación de la discreción con la ocultación de las prácticas homosexuales, o en su relación con la identidad de género o sexual de los hombres, sino en la relación que se establece en muchos perfiles entre decir que se es "discreto" y hacer comentarios plumófobos. Esta relación puede verse en los discursos de perfiles como el de este que describí anteriormente: "Masculino discreto nada de ambiente y sin malos rollos. Busco tío como yo, $100 \%$ masculino y discreto". A veces, las palabras discreto o discreción no aparecen directamente en el perfil, pero lo que se describe en él está íntimamente ligado con ello. Macho, un hombre sin especificación de edad, se escribía en su perfil: "Moreno, delgado, guapete. Busco tío machote sin pluma y fuera de ambiente. Mejor gente de paso con piba o casados jóvenes". Asimismo, aunque los requerimientos de discreción o masculinidad no aparezcan en los perfiles, estos pueden manifestarse al establecerse una conversación en el chat, en donde el hombre con el que se interactúa puede indicar que es "masculino y sin pluma" y que busca "discreción". Esto es algo que ocurre de forma más frecuente cuando el perfil con el que se chatea no incluye fotografías no contiene apenas datos descriptivos. 


\section{EPICENTROS DE LO GAY}

Si hiciese un continuo imaginario con los lugares en los que he realizado trabajo de campo, ubicaría en un extremo lo que llamo epicentros de lo gay, es decir, las zonas urbanas en las que reside una alta concentración de hombres identificados como gays y donde se establecen nichos sociales propios de las subculturas gays - como el barrio de Chueca de Madrid-, y en el otro extremo ubicaría lo que a partir de ahora llamaré zonas de lo no gay, es decir, las áreas no céntricas de una ciudad de mediano tamaño como Córdoba, o incluso los barrios bastante alejados del centro de una capital como Madrid. En las diferentes zonas dentro de este continuo, las prácticas discursivas — tanto textuales como de imagen - relacionadas con la masculinidad, la plumofobia y la discreción iban variando progresivamente según nos acercábamos o nos alejábamos de los epicentros de lo gay.

En este sentido, cuanto más me acercaba a los epicentros de lo gay, se producía una aparente contradicción muy curiosa, aunque lógica si miramos con más atención. En primer lugar, no solo el número de perfiles con fotografías públicas se hacía mayoritario, sino que también crecían de forma exponencial el número de usuarios que mostraban el rostro. Además, y en sintonía con lo afirmado por Gough (1989), la teatralización de los estilos y conductas consideradas masculinas se acrecentaba, algo que se hacía palpable en esas mismas fotografías. Estas mostraban músculos, barbas o ropas deportivas, construyendo esta imagen hiperbólica de la masculinidad a la que me he referido. Pude observar entonces que esa forma de teatralizar la masculinidad se iba intensificando a medida que me iba acercando a un epicentro de lo gay. No obstante, y aquí viene la aparente contradicción, los perfiles con descripciones o nombres haciendo una explícita apología de la masculinidad, con discursos contra la pluma, con requerimientos de discreción o con usuarios que se identificaban como "heteros", decrecían de forma significativa. También pude inferir que en los epicentros de lo gay existía una mayor reflexividad hacia las cuestiones de la masculinidad y la feminidad, así como hombres con sensibilidades más diversas hacia las mismas (Drummond 2005). Aunque en estas zonas sí había perfiles que hacían apología de la masculinidad o discursos explícitos contra la pluma, no eran tan frecuentes como fuera de esas zonas.

Contrariamente, pude observar que en el extremo de lo no gay aparecía un mayor número de perfiles sin fotografías públicas o, al menos, sin imágenes que mostraran el rostro. Asimismo, los discursos textuales explícitos que he descrito como apología y requerimiento la masculinidad eran más frecuentes, así como las llamadas a la discreción y las exigencias contra las plumas. Dado que en estas zonas había muchos más perfiles sin fotografías, así como un mayor número de hombres que requerían una discreción, asociada a querer pasar desapercibido o a un ocultamiento de las prácticas sexuales, el discurso explícito se hacía más necesario. En estas zonas, por tanto, la actitud masculina no tiene solamente una carga teatral, como estrategia para obtener beneficios sexuales, sino que va asociada a otras negociaciones identitarias relacionadas con las ventajas o privilegios de posicionarse socialmente como un hombre de verdad. 


\section{PLUMOFOBIA: EXPERIENCIA, CONCIENCIA Y ACTITUD DÓXICA}

El análisis que hago aquí sobre estas prácticas discursivas en las aplicaciones de contactos para hombres, y concretamente en Wapo, es que este interés de los mismos por cumplir y reproducir normatividades de género está relacionado con las ventajas que presenta ser considerados hombres de verdad y las desventajas que conllevan las maneras de actuar consideradas como femeninas. Como afirma David Forrest (1994), esto brinda a los hombres identificados como gays —o bisexuales, añadiría - la posibilidad de mantener sus privilegios sociales como hombres y escalar en un sistema social dominado por ellos. En una sociedad que durante mucho tiempo ha denegado la masculinidad a los hombres considerados como bomosexuales, estos tienen la oportunidad de asimilar el comportamiento y los valores de la masculinidad heterosexual.

Una cuestión importante que revelan mis entrevistas con hombres conocidos en la aplicación es que muchos de ellos, especialmente los que consideran que no entran dentro de ese estereotipo afeminado, no son conscientes de esta regulación o no han dedicado tiempo a pensar sobre el proceso, no al menos en estos términos. Lo viven de una forma totalmente naturalizada, incuestionada, con lo que Bourdieu llamaría "actitud dóxica" (Bourdieu y Eagleton 2003) y, en muchos casos, como algo deseable. En algunas de las conversaciones mantenidas con los usuarios en el chat de Wapo, o en las entrevistas presenciales con algunos de ellos, suelen manifestar que nunca han pensado en ello —en los términos en que yo lo podía plantear-, y adoptaban una actitud de sorpresa, como el que acaba de oír algo que debería haber sido evidente pero no lo ha sido. Sin embargo, dudo que ese ujamás lo había pensado" se traduzca a que no tiene importancia para ellos porque, como puede verse en los perfiles de Wapo, es un elemento que vertebra sus prácticas, sus discursos y sus expectativas en el campo sexual que conforma la interacción en la aplicación.

De forma contraria, los chicos que sí se consideran a ellos mismos como afeminados o con algún tipo o grado de pluma, sí reflejan de alguna manera una mayor conciencia o reflexividad sobre el fenómeno. A veces, en las entrevistas con los participantes - $\mathrm{O}$ incluso en las conversaciones sobre el tema con conocidos míos-, yo les preguntaba si habían pensado en la razón de este rechazo a la pluma, para ser consciente de la reflexividad emocional (Holmes 2015) que unos y otros dedicaban a la cuestión, o hasta dónde era algo normalizado o dóxico. Por ejemplo, Kilian era un madrileño de 19 años al que entrevisté en persona, en cuyo perfil de Wapo aparecía: "Estáis todos obsesionados con la pluma. Somos maricones, no gallinas". Debido a esto, algunos usuarios le escribían para increparle. "Uno me dijo que [...] los gays quieren estar con hombres. Que por algo les gustan los hombres, porque, si no, para estar con un hombre afeminado, se irían con una mujer", me contaba Kilian. Entonces, hizo la siguiente crítica:

Nosotros somos los primeros homófobos. Si no nos respetamos entre nosotros, ¿por qué pedimos respeto o que nos respeten los demás? Si un gay no respeta a otro gay porque sea más afeminado, porque le guste ir con bolso, con falda o con lo que sea... O porque se quiera travestir... Porque hay muchos que dicen: "Por dios, es que va con tacones... ¡Oh, por dios, un tío con tacones, dios mío!». Es decir, tú eres el primero que le rechaza... ¿Por qué luego vas al orgullo gay? Realmente no vas al orgullo gay a manifestarte, vas a lo mismo. ¿Qué vas, por guapo? La gran mayoría. Yo hablo siempre de la gran mayoría (Kilian, entrevista personal, 15 ene. 2017). 
Puede observarse que Kilian tenía la visión de que la plumofobia es una forma de homofobia interiorizada. No obstante, como he especificado al principio de este trabajo, quiero diferenciar analíticamente entre el concepto de homofobia, al que considero aquí como el rechazo a la homosexualidad o a las personas identificadas como homosexuales, y el de plumofobia, el cual defino aquí como el rechazo a los comportamientos o características consideradas como femeninas en un hombre. Es una distinción muy relevante, una en la que se basa precisamente la idea principal que pretendo defender: que denostar el afeminamiento no va necesariamente unido a tener visiones negativas respecto a las relaciones homosexuales masculinas per se. Estos hombres con prácticas homosexuales agencian todo un sistema de prácticas y discursos que controlan el comportamiento de género de sus pares, pero no están haciendo una campaña que condene sus propias prácticas sexuales, sino las prácticas de género que no se ajustan a las normas sociales de lo que un hombre -o en último término, un hombre deseable— debería ser.

Por otra parte, algunos de los participantes en las entrevistas eran conscientes de que esto es una forma de machismo, pero finalmente respondían a las mismas normas de deseo que la mayoría. Ángel, un chico de 28 años residente en Madrid, me dijo que él había sentido durante mucho tiempo un gran complejo por el tema de la pluma, y que ahora solía increpar en Wapo a los perfiles que fanfarroneaban de masculinidad, de modo contrario a lo que algunos hacían con Kilian. Sin embargo, cuando le pregunté si eso significaba que defendía la pluma, él dijo: "Yo no defiendo la pluma, porque a mí, que me folle uno con mucha pluma, no me provoca ningún placer». Igualmente, Eugenio, un estudiante centroamericano de 26 años residente en Sevilla —al que entrevisté primero en el chat de Wapo, y después en persona en dos ocasiones - especificaba en el perfil que tenía "algo de pluma". Me contaba también en el chat de la aplicación:

- ¿Lo fundamental en ti es que eres joven con algo de pluma?

- Para esta aplicación, sí [...] Es un filtro, no pretendo engañar a nadie, y menos con la gente que anda en busca de súper machos.

- ¿Has sentido rechazo por ese tema en otras ocasiones entonces?

- Sí, algunas veces a la hora de chatear, cuando hacen la pregunta y contesto que sí tengo pluma. Y otras veces al quedar con alguien en persona.

—:Qué suele ocurrir cuando respondes que sí tienes pluma?

- Pues lo típico, fin de la conversación, ya sea que te digan que no es lo que están buscando o simplemente te dejan de hablar.

— ¿Y qué ocurre cuando quedas en persona?

- Pues nada, que te invitan a un café o a dar una vuelta y ya nunca más te vuelven a hablar (Eugenio, entrevista personal, 27 nov. 2015).

Sin embargo, hay que analizar en profundidad la complejidad del asunto, porque, al igual que pasaba con Ángel, esto no significaba que Eugenio defendiese la pluma o considerase que el afeminamiento era una cualidad en valor. Para él, había un nivel "normal" de afeminamiento, y sus gustos respecto a una posible pareja sexual no incluían a las "divas" o "reinonas".

— ¿Cómo te gustan a ti los chicos?

- Si tienen pluma, que sea lo normal, sin caer en divas o reinonas. Activos, que se cuiden un mínimo físicamente, de mi edad o poco más grandes, y de altura similares a mí. 
Físicamente, que sea un conjunto agradable. Y ya lo que termina de enganchar es una buena personalidad (Eugenio, entrevista personal, 27 nov. 2015).

Esta cuestión se veía reflejada también en discursos de perfiles como los de Oso29 en Córdoba: "Soy un tío masculino y 99 \% activo y busco un tío guapete normal (me da igual la pluma pero no admito reinas)". En el caso de Eugenio, cuando quedamos para hacer la primera entrevista en persona, le pregunté por qué especificó en su perfil que tenía "algo de pluma", y él dijo:

-Yo creo que tenía muchas razones... Es que no sabría decir cuál, o sea, es el hecho de decir: "yo estoy buscando algo, pero, ¿qué estoy yo dando a cambio?». En primer lugar, yo me pongo a decir que quiero una persona masculina, pero a lo mejor yo no me veo tan masculino. Entonces, como yo no quiero que me llegue una persona engañándome y diciéndome que es "lo más masculino", pues yo no voy a hacer lo mismo con otra gente, aunque a mí me lo hagan. Para mí es rebajarme a un nivel que no quiero, que es el hecho de decir, "mentir para conseguir algo, aunque sea por compromiso", o lo que tú quieras. Eso por una parte. Por otra, mi misma visión de cómo debe ser un homosexual... O sea, yo siento que la pluma es parte de esa homosexualidad, porque por eso... por eso no somos heteros, porque tenemos un comportamiento que es diferente al de un "macho"... entre comillas. Pero el grado de la pluma es lo que a mí me... me resulta, digamos... esencial. [...]Pero hay otra gente que ya esa pluma es un estilo de vida, las "plumíferas", las... más que plumíferas, yo digo "reinas sin corona".

- Y ésas ya no te parecen tan bien...

—No. A mí eso ya no me parece bien ni normal (Eugenio, entrevista personal, 28 nov. 2015).

Por otra parte, la reacción más frecuente en las entrevistas con hombres que no se consideraban afeminados era el ver todo esto - pensado una vez que el tema ha sido expuesto por mí- como una simple cuestión de gusto, de preferencia personal ${ }^{10}$, como formas naturales a las que se orienta el deseo, la manifestación legítima de lo que a uno le gusta. Como si ese lo que a uno le gusta estuviera desprovisto de formas de poder y de mecanismos sociales de modelación, y como si esa forma legítima de expresarlo no fuera precisamente una forma clara de poder, una forma de decidir sobre lo que tiene legitimidad para ser condenado o nombrado ilegítimo. Está claro que todo esto conforma un sistema de control de género entre pares, una forma de control que los hombres ejercen los unos sobre los otros para alcanzar los privilegios que la hombría trae consigo.

Finalmente, y quizás debido a este uso del concepto de plumofobia que estaba empezando a hacerse eco tímidamente desde los medios (Abundancia 2017; Borraz 2017), en los últimos meses de mi experiencia etnográfica en Wapo comencé a registrar aisladamente perfiles en los que ya aparecían discursos como "no plumofobia", "abternerse plumófobos" o "no plumófobos". Entre otros, registré el perfil de Pepe, un chico joven de 19 años, estudiante en la universidad, que escribía en mayúsculas: "NO PLUMÓFOBOS". Esto me animó a pedirle una entrevista instantánea por el chat, en

\footnotetext{
${ }^{10}$ Robinson (2015) utiliza la idea de "preferencia personal" (personal preference) en su análisis de cómo el concepto de raza afecta a las interacciones en línea en Adam4Adam, una web de ligue y citas entre hombres en los Estados Unidos. Su estudio mostraba que el sistema de filtrado en este sitio web permitía a los usuarios eliminar de la visualización a perfiles con cuerpos raciales, y cómo estas prácticas de exclusión no se consideraban actos racistas, sino como actos de preferencia personal.
} 
la cual se hizo evidente que Pepe estaba empezando a experimentar el rechazo a la pluma. Me dijo que hacía referencia en su perfil por su incipiente actividad en Wapo: "Quedé con un chico que al poco tiempo pasó de mí y luego me enteré de que no le gustaba la pluma y creo que fue por eso". Asimismo, había tenido la oportunidad de descubrir el término plumofobia en redes sociales como Twitter. Parte de la entrevista siguió así:

— ¿Qué pensaste cuando viste usar esa palabra [plumofobia]?

- Pues que qué feo que haya discriminación hasta dentro del colectivo.

— ¿Es algo que tú habías sentido personalmente?

- Personalmente no, que yo recuerde.

— ¿No habías sentido una realidad plumófoba en ningún sentido antes de lo del chico que me has contado?

-A ver, pues hablando con gente notas algunas cosas que te lo pueden insinuar, vaya. Pero no sé, muy sutilmente.

[...]

- ¿Y no habías notado nada aquí en este tipo de aplicaciones?

-Es que no las uso desde hace mucho. Pero sí, claro, aquí más que en cualquier otro sitio. Exigiendo que solo le hable gente "masculina".

— ¿Qué sientes cuando lees los perfiles que ponen esa clase de cosas?

- Pues que es una pena que haya gente así, pero qué se le va a hacer.

- Pero, ¿lo sientes como una mayoría, o como una minoría?

-Aquí lo veo como una mayoría. Aunque quiero pensar que no es así (Pepe, entrevista personal, 21 nov. 2017).

Estas palabras de Pepe, junto con la experiencia de los hombres jóvenes y más adultos entrevistados, mostraban algo que concordaba con mi experiencia etnográfica: que la homonormatividad masculina y plumófoba se experimenta con mucha más intensidad en las aplicaciones de contactos sexuales -más exigencia explícita cuanto más explícitamente sexual es la aplicación-. Fuera de ellas, la realidad social de estos hombres es más compleja, y la cuestión de la masculinidad y la feminidad es una continua negociación (Levine 1998; Drummond 2005).

\section{REFLEXIONES FINALES: LA PLUMOFOBIA Y EL CAPITAL SIMBÓLICO DE LA MAS- CULINIDAD}

Como he argumentado a lo largo de este trabajo, considero Wapo como un campo sexual que refleja y a la vez produce las normas de comportamiento y deseabilidad que se producen en el mismo. Por tanto, defiendo que esta cuestión de gusto, es decir, esta hegemonía de un modelo hiperbólico de lo viril que rige los criterios de deseabilidad y de comportamiento de género en la aplicación, se debe a la imitación, asimilación e internalización de estructuras de deseo hegemónicas en los campos en los que los hombres con prácticas homosexuales son continuamente socializados. Según esta hipótesis, con el tiempo, "la exposición al campo produce un efecto de socialización a la vez que los individuos se van familiarizando con él, van asimilándolo y erotizando cada vez más su lógica, hasta que el deseo aparece como algo natural y automático, como una segunda naturaleza" (Green 2014: 40, traducción propia). Primero, los hombres se acostumbran y se hacen receptivos a las normas socia- 
les sexuales, y después se produce "la internalización inconsciente de la estructura de deseo del campo en el habitus erótico del actor, de tal forma que se convierte en una disposición independiente del campo sexual en sí" (Green 2014: 40, traducción propia). De esta manera, la comunidad virtual en Wapo conforma un campo sexual con unos criterios de deseabilidad jerarquizantes, y el ideal masculino se convierte en una expectativa a cumplir por todo hombre que pretenda resultar deseable.

Asimismo, he argumentado que esta masculinización de las prácticas y representaciones asociadas a la homosexualidad masculina da a los hombres que la practican la posibilidad de conservar privilegios asociados a la hombría y al dominio masculino. Por tanto, lo que podría ser visto como una forma de resistencia, puede verse al mismo tiempo como una estrategia de recuperación y conservación de poder, como una reacción a los privilegios perdidos al no haber sido considerados hombres de verdad. Una estrategia de poder/resistencia que los lleva hasta otras estructuras de poder que se solapan con las anteriores (Abu-Lughod 1990), a ser sometidos a nuevas formas de control, pues conduce en la práctica a un sistema de regulación con normas rígidas de género (auto)impuestas y (auto)vigiladas.

Este sistema de control trae asociados unos beneficios estratégicos. El más claro es la adaptación al sistema de deseo, y la obtención de bonificación sexual. No obstante, en muchos sentidos, esto es fuente de presión en sí para los hombres, pues esta adopción de estilos hipermasculinos está basada en una autoconciencia de ser objetos sexuales y, por ende, en una fetichización de la persona, a la que se le marca una expectativa abstracta de un modelo de masculinidad que nadie puede lograr o ser (Gough 1989; Drummond 2005).

Finalmente, como también he argumentado, una de las ventajas estratégicas está relacionada con la discreción. Como afirma Forrest, "aparte de la amenaza real de los "matones de maricas", es importante recordar que la mayor parte de los hombres gay pueden, y normalmente lo hacen, pasar por "heteros", y así continuar obteniendo ventajas de su posición como hombres" (Forrest 1994: 106). De manera frecuente, la mención o llamada a la "discreción" — definirse como y/o requerir a alguien discreto- en Wapo va unida al discurso de la masculinidad — definirse como y/o requerir a alguien masculino- . En estos casos, puede inferirse una vinculación entre masculinidad y discreción, en la que la actitud masculina es una ventaja estratégica para pasar desapercibido, o para llevar a cabo las prácticas de forma oculta y no formar parte de una identidad generalizada gay que los situaría —es de suponer por el esfuerzo que ponen en que así no sea- en un lugar social donde no querrían estar. El hecho de asumir actitudes consideradas como masculinas hace que sus prácticas sexuales no creen tanta tensión con la figura tradicional de hombre, ocupando así las posiciones sociales que correspondan a un hombre de verdad, y beneficiándose de los privilegios que esta figura traiga asociada.

Como resultado, la actividad sexual se convierte también en un instrumento que controla el comportamiento de género: si el estímulo a conseguir son los cuerpos, el sexo como imperativo de realización, la manera más efectiva de masculinizar a estos hombres es que el criterio de deseabilidad sexual sea el ideal masculino. La deserotización de la feminidad, de los hombres con pluma, de la figura de las locas, hace que estos hombres asuman este modelo viril hiperbólico para conseguir lo deseado, que es a su vez ser deseado por el resto de hombres dentro de esta estructu- 
ra de deseo histórica y socialmente constituida en la que el capital sexual gira en torno a códigos asociados a la idea cultural de masculinidad.

He definido estos normatividades, sostenidas mismamente por los hombres con prácticas o identidades homosexuales/bisexuales, como una manifestación de la plumofobia. Evalúo esta tendencia estructural en términos de un proceso de negociación de poder/privilegio, de reapropiación del capital simbólico de la masculinidad: si los hombres con prácticas e/o identidades homosexuales negocian su aparición como masculina y/o discreta es porque negocian su posición de poder dentro de un sistema en el que la masculinidad y la identidad heterosexual traen asociadas una posición privilegiada.

\section{BIBLIOGRAFÍA CITADA}

Abundancia, Rita. 2017. "Plumofobia: puedes ser gay o lesbiana, pero que no se note». El País 27 jun. Disponible en: <https://smoda.elpais.com/moda/plumofobia-puedes-gay-lesbiana-no-se-note/>. Fecha de acceso: 24 jul. 2018.

Abu-Lughod, Lila. 1990. "The Romance of Resistance: Tracing Transformations of Power through Bedouin Women". American Ethnologist 17(1): 41-55.

Ahlm, Jody. 2017. "Respectable promiscuity: digital cruising in an era of queer liberalism" Sexualities 20(3): 364-379.

Annes, Alexis y Meredith Redlin. 2012. "The Careful Balance of Gender and Sexuality: Rural Gay Men, the Heterosexual Matrix, and "Effeminophobia". Journal of Homosexuality 59(2): 256-288.

Ardèvol, Elisenda, Marta Bertrán, Blanca Callén y Carmen Pérez. 2003. "Etnografía virtualizada: la observación participante y la entrevista semiestructurada en línea». Athenea Digital 3: 72-92.

Ariza, Saúl. En prensa. "Homosexuality as Practice and the Social Implications of Representation". Studies in Gender and Sexuality.

Batiste, Dominique Pierre. 2013. "“0 Feet Away": The Queer Cartography of French Gay Men's GeoSocial Media Use". Anthropological Journal of European Cultures 22(2): 111-132.

Bergling, Tim. 2001. Sissyphobia: gay men and effeminate behavior. Filadelfia: Haworth Press.

Blachford, Gregg. 1981. "Male dominance and the gay world", en Kenneth Plummer (ed.), The making of the modern homosexual: 184-210. Londres: Hutchinson.

Blackwell, Courtney, Jeremy Birnholtz y Charles Abbott. 2015. "Seeing and Being Seen: Co-Situation and Impression Formation Using Grindr, a Location-Aware Gay Dating App". New Media and Society 17(7): 1117-1136.

Blackwood, Evelyn. 1985. "Breaking the Mirror: The Construction of Lesbianism and the Anthropological Discourse on Homosexuality". Journal of Homosexuality 11(3-4): 1-17.

Bonner-Thompson, Carl. 2017. "The Meat Market": Production and Regulation of Masculinities on the Grindr Grid in Newcastle-upon-Tyne, UK". Gender, Place and Culture 24(11): 1611-1125.

Bolin, Anne. 1996. "Traversing Gender: Cultural Context and Gender Practices", en Sabrina P. Ramet (ed.), Gender reversals and gender cultures: 22-51. Londres/Nueva York: Routledge.

Bord, Brot. 2013. "Somewhere under the rainbow: mercantilización y asimilación de la disidencia sexual", en Miriam Solá y Elena Urko (eds.), Transfeminismos: epistemes, fricciones y flujos: 153165. Tafalla: Txalaparta.

Borraz, Marta. 2017. "Gay sí, pero que no se note». El Diario.es 16 may. Disponible en: < https:// www.eldiario.es/sociedad/Gay-homofobia-plumofobia_0_644285773.html>. Fecha de acceso: 30 jul 2018.

Bourdieu, Pierre y Terry Eagleton. 2003. "Doxa y vida cotidiana: una entrevista", en Slavoj Žižek (ed.), Ideología: un mapa de la cuestión: 295-308. Madrid: Fondo de Cultura Económica de España.

Cabezas González, Almudena y David Berná Serna. 2013. "Cuerpos, espacios y violencias en los regímenes biopolíticos de la Modernidad: de maricas y homosexuales habitando "lo femenino". Política y Sociedad 50(3): 771-802. 
Cáceres, Rafael y José María Valcuende. 2014. "Globalización y diversidad sexual: gays y mariquitas en Andalucía". Gazeta de Antropologia 30(3), artículo 7. Disponible en: <http://hdl.handle.net/ 10481/33814>.

Coll-Planas, Gerard. 2010. La voluntad y el deseo. La construcción social del género y la sexualidad: el caso de lesbianas, gays y trans. Madrid: Egales.

Connell, Raewyn. 1995. Masculinities. Cambridge: Polity Press.

Couto, Walter, Fábio Morelli, Dolores Galindo y Leonardo Lemos de Souza. 2016. "Práticas sexuais em geolocalização entre homens: corpos, prazeres, tecnologias”. Athenea Digital 16(2): 169-193.

Drummond, Murray. 2005. "Men's Bodies: Listening to the Voices of Young Gay Men". Men and Masculinities 7(3): 270-290.

Edwards, Tim. 1990. "Beyond Sex and Gender: Masculinity, Homosexuality and Social Theory", en Jeff Hearn y David Morgan (eds.), Men, Masculinities and Social Theory: 110-123. Londres: Unwin Hyman.

Edwards, Tim. 1994. Erotics \& Politics: Gay Male Sexuality, Masculinity and Feminism. Londres: Routledge.

Enguix, Begonya y Erick Gómez Narváez. 2018. "Masculine Bodies, Selfies, and the (Re)Configurations of Intimacy". Men and Masculinities 21(1): 112-130.

Eguchi, Shinsuke. 2011. "Negotiating Sissyphobia: A Critical/Interpretive Analysis of One "Femme" Gay Asian Body in the Heteronormative World". The Journal of Men's Studies 19(1): 37-56.

Forrest, David. 1994. "We're Here, We're Queer, and We're Not Going Shopping”, en Andrea Cornwall y Nancy Lindisfarne (eds.), Dislocating Masculinity: Comparative Ethnographies: 97-110. Londres: Routledge.

Gómez Beltrán, Iván. 2016. "Resistencias estrateìgicas a la feminidad masculina en aplicaciones moìviles (app) de contacto homosexual entre varones: "las plumas a otro lado" ". Arte y políticas de identidad 15: 137-154.

Gough, Jamie. 1989. "Theories of Identity and the Masculinization of the Gay Man", en Simon Shephered y Mick Wallis (eds.), Coming on Strong: Gay Politics and Culture: 119-136. Londres: Unwin Hyman.

Green, Adam Isaiah. 2008. "The Social Organization of Desire: The Sexual Fields Approach". Sociological Theory 26(1): 25-50.

Green, Adam Isaiah. 2011. "Playing the (Sexual) Field: The Interactional Basis of Systems of Sexual Stratification". Social Psychology Quarterly 74(3): 244-266.

Green, Adam Isaiah. 2014. "The sexual fields framework", en Adam Isaiah Green (ed.), Sexual Fields: Toward a Sociology of Collective Life: 25-56. Chicago: University of Chicago Press.

Guasch, Oscar. 1991. La sociedad rosa. Barcelona: Anagrama.

Guasch, Oscar. 2000. La crisis de la heterosexualidad. Barcelona: Leartes.

Guasch, Oscar. 2011. "Social Stereotypes and Masculine Homosexualities: The Spanish Case". Sexualities 14(5): 526-543.

Harris, Daniel. 1999. The Rise and Fall of Gay Culture. Nueva York: Ballantine Books.

Hekma, Gert. 1994. "A Female Soul in a Male Body": Sexual Inversion as Gender Inversion in Nineteenth-Century Sexology", en Gilbert Herdt (ed.), Third Sex, Third Gender: Beyond Sexual Dimorphism in Culture and History: 213-240. Nueva York: Zone Books.

Holmes, Mary. 2015. "Researching Emotional Reflexivity". Emotion Review 7(1): 61-66.

Humphries, Martin. 1985. "Gay machismo", en Andy Metcalf y Martin Humphries (ed.), The sexuality of men: 70-85. Londres: Pluto Press.

Jaspal, Rusi. 2017. "Gay Men's Construction and Management of Identity on Grindr". Sexuality and Culture 21(1): 187-204.

Kimmel, Michael. 1994. "Masculinity as Homophobia: Fear, Shame and Silence in the Construction of Gender Identity", en Harry Brod y Michael Kaufman (eds.), Theorizing masculinities: 134-151. Thousand Oaks: SAGE.

Levine, Martin. 1998. Gay macho: life and death of the gay clone. Nueva York: New York University Press.

Marshal, John. 1981. "Pansies, Perverts and Macho Men: Changing Conceptions of Male Homosexuality", en Kenneth Plummer (ed.), The making of the modern homosexual: 133-154. Londres: Hutchinson. 
Martin, John Levi y Matt George. 2006. "Theories of Sexual Stratification: Toward an Analytics of the Sexual Field and a Theory of Sexual Capital". Sociological Theory 24(2): 107-132.

Miles, Sam. 2017. "Sex in the Digital City: Location-Based Dating Apps and Queer Urban Life". Gender, Place and Culture 24(11): 1595-1610.

Miller, Brandon. 2015. "Dude, Where's Your Face?” Self-Presentation, Self-Description and Partner Preferences on a Social Networking Application for Men Who Have Sex with Men: A Content Analysis". Sexuality and Culture 19(4): 637-658.

Mira, Alberto. 2004. De Sodoma a Chueca: una bistoria cultural de la homosexualidad en España en el siglo $X X$. Barcelona/Madrid: Egales.

Olmeda, Fernando. 2004. El látigo y la pluma: bomosexuales en la España de Franco. Madrid: Oberón

Pichardo, José Ignacio. 2012. "El estigma hacia personas lesbianas, gays, bisexuales y transexuales", en Elena Gaviria, Cristina García-Ael y Fernando Molero (eds.), Investigación-acción: aportaciones de la investigación a la reducción del estigma: 111-125. Madrid: Sanz y Torres.

Reynolds, Chelsea. 2015. "I Am Super Straight and I Prefer You be Too”: Constructions of Heterosexual Masculinity in Online Personal Ads for "Straight" Men Seeking Sex With Men". Journal of Communication Inquiry 39. doi: <https://doi.org/10.1177/0196859915575736>.

Richardson, Niall. 2009. "Effeminophobia, Misogyny and Queer Friendship: The Cultural Themes of Channel 4's Playing It Straight. Sexualities 12(4): 525-544.

Robinson, Brandon Andrew. 2015. "Personal Preference" as the New Racism". Sociology of Race and Ethnicity 1(2): 317-330.

Sabuco, Assumpta y Jose María Valcuende. 2003. "La "homosexualidad" como representación hiperbólica de la masculinidad", en José María Valcuende y Juan Blanco (eds.), Hombres: la construcción cultural de las masculinidades: 135-154. Madrid: Talasa.

Segal, Lynn. 1994. Slow Motion: Changing Masculinities, Changing Men. Londres: Virago.

Valcuende del Río, José María. 2010. "Sexo entre hombres: los límites de la masculinidad". Revista Internacional de Ciencias Sociales y Humanidades, SOCIOTAM 20(1): 11-37.

Viñuales, Olga. 2000. Identidades lésbicas. Barcelona: Bellaterra.

Ward, Jane. 2008. "Dude-Sex: White Masculinities and "Authentic" Heterosexuality among Dudes Who Have Sex with Dudes”. Sexualities 11(4): 414-434.

Welzer-Lang, Daniel. 2002. "La crisis de las masculinidades: entre cuestionamientos feministas y críticas contra el heterosexismo", en Ana Rincón (ed.), Congreso Internacional: Los Hombres ante el Nuevo Orden Social: 53-76. Vitoria-Gasteiz: Emekunde, Instituto Vasco de la Mujer.

Wiele, Chad van de y Stephanie Tom Tong. 2014. "Breaking boundaries: the uses \& gratifications of Grindr", en Proceedings of the 2014 ACM International Joint Conference on Pervasive and Ubiquitous Computing, September 13-17, 2014, Seattle, WA, USA: 619-630. Nueva York: Association for Computing Machinery.

Withey, Josh. 2016. "Over Half of "Straight Acting" Gay Guys Think "Feminine Gay Men Give Them a Bad Reputation"”. Gay Times 27 oct. Disponible en: <https://www.gaytimes.co.uk/news/52306/ over-half-straight-acting-gay-guys-think-feminine-gay-men-give-bad-reputation/>. Fecha de acceSo: 24 jul. 2018.

Yeo, Tien Ee Dominic y Tsz Hin Fung. 2018. "Mr Right Now”: Temporality of Relationship Formation on Gay Mobile Dating Apps". Mobile Media and Communication 6(1): 3-18.

Fecha de recepción: 3 de julio de 2017

Fecha de aceptación: 5 de abril de 2018 